\title{
Clinical Usefulness of Aripiprazole Treatment in a Girl with Prader-Willi Syndrome and Psychosis
}

\author{
Wolfgang Briegel \\ Department of Child and Adolescent Psychiatry, Psychosomatics and Psychotherapy, Leopoldina Hospital, Schweinfurt, Germany
}

\begin{abstract}
Prader-Willi syndrome (PWS) is a quite rare multi-systemic genetic disorder strongly associated with psychiatric illness in adults, especially psychosis. This report presents a 16-year-old female with PWS and symptoms of brief psychotic disorder with a complete resolution of symptoms under aripiprazole medication. However, an exacerbation occurred after aripiprazole reduction. Apart from a weight gain of about $2 \mathrm{~kg}$ over the course of two years, no adverse effects could be found. This first report on the use of aripiprazole in a subject with PWS and psychosis suggests that aripiprazole might be a promising treatment approach in this distinct group of patients.
\end{abstract}

KEY WORDS: Prader-Willi syndrome; Aripiprazole; Psychosis; Adolescent; Case reports.

\section{INTRODUCTION}

Prader-Willi syndrome (PWS; Online Mendelian Inheritance in Man, Nr. 176270) is a generally sporadic, multisystemic genetic disorder with an estimated birth incidence of $1 / 15.000$ to $1 / 30.000 .{ }^{1)}$ It results from failure of expression of paternally inherited genes in the critical region at 15q11-q13 which in most cases is caused by a deletion of paternal origin (about $70 \%$ ) or maternal uniparental disomy (mUPD) of chromosome 15 (about $25 \%)^{2)}$ PWS is characterized by severe perinatal muscular hypotonia and feeding problems in early infancy, followed by excessive eating and the development of overweight (unless eating is externally controlled). ${ }^{3)}$ Hyperphagia, hypogonadism and short stature (if not treated with growth hormone) are typical symptoms related to hypofunction of the hypothalamus. ${ }^{3)}$ Dysmorphic facial features, strabismus and scoliosis are further frequent so-

Received: February 7, 2017 / Revised: May 3, 2017

Accepted: May 10, 2017

Address for correspondence:

Wolfgang Briegel, Priv.-Doz. Dr. med. habil.

Klinik für Kinder- und Jugendpsychiatrie, Psychosomatik \&

Psychotherapie, Leopoldina-Krankenhaus, Gustav-Adolf-Str. 4, 97422 Schweinfurt, Germany

Tel: +49-9721-720-3370, Fax: +49-9721-720-2901

E-mail: wbriegel@leopoldina.de

ORCID: https://orcid.org/0000-0002-8253-5070 matic signs. ${ }^{2)}$

Additionally, PWS is characterized by a distinctive neuropsychiatric phenotype including intellectual disabilities (borderline to mild/moderate mental retardation) with delayed motor and language development as well as behavior disturbances like temper tantrums, mood fluctuations, skin-picking, and obsessive-compulsive behavior. ${ }^{4}$ Studies in adults have found increased prevalence rates of major psychiatric illness with predominantly psychosis. ${ }^{5)}$ There is very limited knowledge about the effectiveness of psychopharmacological interventions in subjects with PWS and psychiatric disorders, especially among children and adolescents. ${ }^{6)}$ For a summary see Table $1 .^{7-13)}$

The author herein reports on a 16-year-old German female with the mUPD-subtype of PWS and psychosis who was treated with aripiprazole.

\section{CASE}

The patient was a Caucasian female aged 16 years and 9 months. Five days before referral, the family had returned from one of their frequent cruises, she had started to show lack of distance towards strangers, aggressive behavior (e.g., biting her mother, throwing objects, swearing at her parents), and increasing agitation (including temper tantrums and sleep disturbances). She had told her mother

(ㄷ) This is an Open-Access article distributed under the terms of the Creative Commons Attribution Non-Commercial License (http://creativecommons.org/licenses/by-nc/4.0) which permits unrestricted non-commercial use, distribution, and reproduction in any medium, provided the original work is properly cited. 
Table 1. Antipsychotics and antidepressants in children and adolescents with Prader-Willi-Syndrome

\begin{tabular}{|c|c|c|c|c|c|c|}
\hline \multirow{2}{*}{$\begin{array}{l}\text { Age }(y r) / \\
\text { Gender }\end{array}$} & \multirow{2}{*}{$\begin{array}{l}\text { Psychotropic substance } \\
\text { (dose, } \mathrm{mg} / \mathrm{d} \text { ) }\end{array}$} & \multicolumn{3}{|c|}{ Efficiency } & \multirow{2}{*}{ Side effects } & \multirow[b]{2}{*}{ Reference } \\
\hline & & $\begin{array}{l}\text { Aggressive } \\
\text { behavior }\end{array}$ & $\begin{array}{l}\text { Obsessive-compulsive } \\
\text { behavior }\end{array}$ & Weight & & \\
\hline \multicolumn{7}{|l|}{ Antidepressants } \\
\hline 9/female & Fluoxetine $(60)+$ naltrexone $(60)$ & Reduction & - & Reduction & None reported & 7 \\
\hline 11/female & Fluoxetine (30) & No reduction & No reduction & - & None reported & 8 \\
\hline 11/female & Sertraline (75) & No reduction & No reduction & - & None reported & 8 \\
\hline 13/female & Fluoxetine (10) & - & - & No change & Psychosis & 9 \\
\hline $14 /$ male & Fluoxetine (60) & Increase & Reduction & Increase & None reported & 10 \\
\hline $17 /$ female & Fluoxetine (40) & Reduction & - & Reduction & None reported & 11 \\
\hline 14/male & Fluvoxamine (50-200) & Increase & Reduction & Increase & None reported & 10 \\
\hline \multicolumn{7}{|l|}{ Antipsychotics } \\
\hline 11/female & Aripiprazole (5-10) & Reduction & Reduction & - & None reported & 8 \\
\hline $11 /$ male & Risperidone (0.5-1.5) & Reduction & - & Reduction & None reported & 12 \\
\hline $15 /$ male & Risperidone (1.5) & Reduction & Reduction & Increase & None reported & 13 \\
\hline
\end{tabular}

- , no information.

that she was electrically charged and that others should not touch her. She refused to eat and had started bed-wetting.

The patient was born at 40 weeks' gestation via C-section due to breech presentation and cardiotocographic abnormalities. She had low birth weight $(2,070 \mathrm{~g}$, $<10$ th percentile), club feet and showed muscular hypotonia with consecutive feeding problems. She was diagnosed with complete atrioventricular channel and atrial septum defect which required surgical revision (at the age of five months). A global developmental delay became apparent at the age of 5 months. At the age of 7 months, the diagnosis of PWS, mUPD subtype, was established by molecular genetic testing. Assessment of cognitive functioning with the Kaufman Assessment Battery for Children $(\mathrm{KABC})^{14)}$ at the age of five years showed a Full Scale Intelligence Quotient of 48 (sequential processing, 57; simultaneous processing, 41). Stressful life events had been several operations during childhood (heart defect, club feet). The patient kept to a strict diet plan (1,300 kcal per day) to avoid overeating. At clinical presentation she did not take any medication.

Her immediate family lived together and consisted of her biological parents who reported that they had no history of mental disorder.

On physical examination the patient showed short stature $(126 \mathrm{~cm},<1$ st percentile), obesity $(54.5 \mathrm{~kg}$, body mass index: $34.3 \mathrm{~kg} / \mathrm{m}^{2}$; $>99$ th percentile), microcephaly $(48.5 \mathrm{~cm},<3$ rd percentile), muscular hypotension, small hands, club feet, and strabismus. During mental examina- tion, she seemed very irritable, anxious and agitated. She showed disorganized speech with frequent incoherence, stuttering and verbigerations (e.g., "I swear"), reduced eye contact, signs of hallucinatory behaviors, and paranoid delusions. Laboratory tests including urine toxicology screening revealed regular results. A brain magnetic resonance imaging showed an old lacunar lesion located at the right periventricular basal ganglia but no signs of an infection or neoplasia.

Admission diagnosis was brief psychotic disorder (the Diagnostic and Statistical Manual of Mental Disorders 5th edition: 298.8). It was decided to start treatment with aripiprazole ( $2 \mathrm{mg}$ per day) and lorazepam ( $0.75 \mathrm{mg}$ per day) for combined antipsychotic and anxiolytic effects. By increasing aripiprazole doses to $5 \mathrm{mg}$, target serum levels could be established (118-131 $\mathrm{\mu g} / \mathrm{L}$; target range for adults, 50-350 $\mu \mathrm{g} / \mathrm{L})$, and psychotic symptoms continuously decreased. The patient's social contacts improved gradually and she was well integrated among her co-patients despite her intellectual disabilities. After some overnight trials at home and up to four hours at school per day, the patient was finally discharged on the 54th hospital day. At this time, her parents reported that she was 90\% the same as before admission - a happy and curious girl without any behavior problems. Psychotic symptoms had completely disappeared and her body weight had remained stable $(54.3 \mathrm{~kg})$.

The patient was followed up in the outpatient department during the next months. Seven months after discharge from hospital and with an aripiprazole level of 95 
$\mu \mathrm{g} / \mathrm{L}$, aripiprazole was reduced to $4 \mathrm{mg}$ per day. Three months later, while being again on a cruise, the patient developed another episode similar to the first one but without definite hallucinations. She avoided eye contact with others, squinted and at times, she even seemed catatonic. During her second hospital stay (27 days), aripiprazole was increased to $7 \mathrm{mg}$ per day (serum level, 140 $\mu \mathrm{g} / \mathrm{L})$ resulting in a relatively quick termination of psychotic symptoms. Under a strict diet plan (1,300 kcal per day) her body weight could be reduced from $59.6 \mathrm{~kg}$ at admission to $56.7 \mathrm{~kg}$ at discharge. Cruises and journeys were discussed as possible stressors causing psychotic episodes. The patient and her parents agreed on the recommendation to avoid potentially stressful situations like frequent shore leaves. After discharge from hospital, her parents reported that the now 18-year-old female was $100 \%$ the same as before her first psychotic episode. Maintaining aripiprazole $7 \mathrm{mg}$ she was followed up in our child and adolescent outpatients department for the next six months until shortly before her 19th birthday. Despite of various stressors like cruises, journeys, breakup from her boyfriend, and conflicts with another student at school her psychological condition remained good and her weight could be stabilized at about $56 \mathrm{~kg}$.

Written informed consent was obtained from both the patient and her parents for case report.

\section{DISCUSSION}

PWS is a quite rare genetic disorder. There is very limited knowledge about the presence and progression of psychiatric disorders in children and adolescents with PWS. While studies in adults have found significantly increased prevalence rates of psychosis (about $80 \%$ of psychiatric disorders) and especially among subjects with the mUPD subtype, psychotic symptoms seem to be quite rare among children and adolescents with PWS (about $2 \%)^{5,15,16)}$

A recent review on psychotropic treatments in PWS indicated a poor literature base with few controlled trials and many case reports. ${ }^{6)}$ Nevertheless, the authors identified promising treatment effects with risperidone for psychotic symptoms associated with mUPD, ${ }^{6)}$ although all studies they cited dealt with behavior problems like aggression and emotional lability and not with psychotic episodes. ${ }^{17)}$ Interestingly, three reports on risperidone treatment in PWS subjects have found a positive effect on weight and appetite, ${ }^{6}$ ) which is in contrast to extensive data from the general population showing moderate incidence of weight gain for risperidone. ${ }^{18)}$

Unaware of the findings on risperidone, aripiprazole treatment was initiated in the above described patient because of the following reasons: (i) aripiprazole, a partial dopamine agonist whose major action is at the D2 and 5-HT1A receptor sites, while also acting as an antagonist at serotonin 5-HT2A receptors, is approved for the treatment of schizophrenia and bipolar mania in adolescents and adults in Germany like in many other countries; (ii) aripiprazole has been found to show very low incidence of weight gain, a crucial aspect in the treatment of subjects with $\mathrm{PWS}^{18)}$; and (iii) aripiprazole provides some additional advantages over other antipsychotics in terms of extrapyramidal symptoms, sedation and hyperprolactinemia. $^{19)}$

To the author's knowledge, there has been only one report on the use of aripiprazole in a subject with PWS so far, the case report of a child with obsessive compulsive disorder and aggressive behaviors. ${ }^{11)}$

Taking into account psychological symptoms and their onset as well as the course of the patient's illness, brief psychotic disorder seemed to be the most accurate psychiatric diagnosis in our patient. However, standard criteria are often difficult to apply in diagnosing psychopathology in individuals with intellectual disabilities. Additionally, psychiatric illness in people with PWS has been found to be atypical resembling an atypical affective disorder with or without psychotic symptoms. ${ }^{5,20)}$

Regardless of the exact diagnosis, aripiprazole 5-7 mg per day demonstrated good efficacy in our patient leading to a complete resolution of psychotic symptoms. Low aripiprazole levels in combination with stress due to another cruise might have also resulted in an exacerbation of the disorder. In contrast to the excellent effects on psychological symptoms, a weight gain of about $2.0 \mathrm{~kg}$ could be found under aripiprazole treatment over the course of two years. However, it remains unclear whether this increase in weight was due to medication or to reduced physical activity. Fortunately, no other possible side effects of aripiprazole medication could be observed.

To sum it up, aripiprazole might be a promising treatment approach in subjects with PWS and psychosis. However, studies with larger samples are needed to eval- 
uate efficacy, benefits and side effects of antipsychotics in this distinct group of patients. In doing so, special attention should be given to appetite and metabolic side effects like weight gain.

\section{Acknowledgments}

The author wants to thank the patient and her parents for their willingness to share their experiences.

\section{REFERENCES}

1. Cassidy SB, Driscoll DJ. Prader-Willi syndrome. Eur J Hum Genet 2009;17:3-13.

2. Angulo MA, Butler MG, Cataletto ME. Prader-Willi syndrome: a review of clinical, genetic, and endocrine findings. I Endocrinol Invest 2015;38:1249-1263.

3. Driscoll DJ, Miller JL, Schwartz S, Cassidy SB. Prader-Willi syndrome. 1998 Oct 6 lupdated 2016 Feb 4, cited 2017 Nov 10]. In: Pagon RA, Adam MP, Ardinger HH, Wallace $S E$, Amemiya $A$, Bean LJH, et al., editors. GeneReviews ${ }^{\circledR}$ [Internet]. Seattle (WA): University of Washington, Seattle; 1993-2017. Available from: https://www.ncbi.nlm.nih.gov/ books/NBK1330/

4. Ho AY, Dimitropoulos A. Clinical management of behavioral characteristics of Prader-Willi syndrome. Neuropsychiatr Dis Treat 2010;6:107-118.

5. Sinnema M, Boer $\mathrm{H}$, Collin $\mathrm{P}$, Maaskant MA, van Roozendaal $\mathrm{KE}$, Schrander-Stumpel CT, et al. Psychiatric illness in a cohort of adults with Prader-Willi syndrome. Res Dev Disabil 2011; 32:1729-1735.

6. Bonnot O, Cohen D, Thuilleaux D, Consoli A, Cabal S, Tauber M. Psychotropic treatments in Prader-Willi syndrome: a critical review of published literature. Eur J Pediatr 2016;175: 9-18.

7. Benjamin E, Buot-Smith T. Naltrexone and fluoxetine in Prader-Willi syndrome. J Am Acad Child Adolesc Psychiatry 1993;32:870-873.

8. Akça ÖF, Yilmaz S. Aripiprazole in the treatment of obsessive compulsive disorder and aggressive behaviors in a child with Prader Silli syndrome: a case report. I Clin Psychopharmacol
2016;36:526-528.

9. Hergüner S, Mukaddes NM. Psychosis associated with fluoxetine in Prader-Willi syndrome. I Am Acad Child AdolesC Psychiatry 2007;46:944-945.

10. Kohn Y, Weizman A, Apter A. Aggravation of food-related behavior in an adolescent with Prader-Willi syndrome treated with fluvoxamine and fluoxetine. Int I Eat Disord 2001;30: 113-117.

11. Dech B, Budow L. The use of fluoxetine in an adolescent with Prader-Willi syndrome. I Am Acad Child Adolesc Psychiatry 1991;30:298-302.

12. Araki S, Ohji T, Shiota N, Dobashi K, Shimono M, Shirahata A. Successful risperidone treatment for behavioral disturbances in Prader-Willi syndrome. Pediatr Int 2010;52:e1-e3.

13. Durst R, Rubin-Jabotinsky K, Raskin S, Katz G, Zislin J. Risperidone in treating behavioural disturbances of PraderWilli syndrome. Acta Psychiatr Scand 2000;102:461-465.

14. Kaufman AS, Kaufman NL. Kaufman assessment battery for children K-ABC. 8th ed. German version by Melchers P and Preuß U. Frankfurt am Main:Pearson Assessment;2009.

15. Yang L, Zhan GD, Ding J, Wang HJ, Ma D, Huang GY, et al. Psychiatric illness and intellectual disability in the PraderWilli syndrome with different molecular defects--a meta analysis. PLoS One 2013;8:e72640.

16. Lo ST, Collin PJ, Hokken-Koelega AC. Psychiatric disorders in children with Prader-Willi syndrome-Results of a 2-year longitudinal study. Am J Med Genet A 2015;167A:983-991.

17. Briegel W. Neuropsychiatric aspects of Prader-Willi syndrome-a review. Z Kinder Jugendpsychiatr Psychother 2017;14:1-8.

18. Ventriglio A, Gentile A, Stella E, Bellomo A. Metabolic issues in patients affected by schizophrenia: clinical characteristics and medical management. Front Neurosci 2015;9:297.

19. Safer DJ, Calarge CA, Safer AM. Prolactin serum concentrations during aripiprazole treatment in youth. I Child Adolesc Psychopharmacol 2013;23:282-289.

20. Soni S, Whittington J, Holland AJ, Webb T, Maina EN, Boer H, et al. The phenomenology and diagnosis of psychiatric illness in people with Prader-Willi syndrome. Psychol Med 2008; 38:1505-1514. 